\title{
Attention as a process of selection, perception as a process of representation, and phenomenal experience as the resulting process of perception being modulated by a dedicated consciousness mechanism
}

\author{
Talis Bachmann* \\ Department of Psychology and Institute of Law, University of Tartu, Tartu, Estonia
}

Edited by:

Naotsugu Tsuchiya, RIKEN, Japan

Reviewed by:

Michael Posner, University of Oregon, USA

Catherine Tallon-Baudry, Universite

Pierre et Marie Curie, France

Bahador Bahrami, University College

London, UK

*Correspondence:

Talis Bachmann, Department of

Psychology and Institute of Law,

University of Tartu (Tallinn branch),

Kaarli puiestee 3, Tallinn 10119,

Estonia.

e-mail: talis.bachmann@ut.ee
Equivalence of attention and consciousness is disputed and necessity of attentional effects for conscious experience has become questioned. However, the conceptual landscape and interpretations of empirical evidence as related to this issue have remained controversial. Here I present some conceptual distinctions and research strategies potentially useful for moving forward when tackling this issue. Specifically, it is argued that we should carefully differentiate between pre-conscious processes and the processes resulting in phenomenal experience, move the emphasis from studying the effects of attention on the modality-specific and feature-specific perception to studying attentional effects on panmodal universal attributes of whatever conscious experience may be the case, and acknowledge that there is a specialized mechanism for leading to conscious experience of the pre-consciously represented contents autonomous from the mechanisms of perception, attention, memory, and cognitive control.

Keywords: attention, consciousness, phenomenal experience, mechanism of consciousness

\section{INTRODUCTION}

In terms of subjective intentionality, unity and integration consciousness is panmodal or supramodal, but in terms of qualitative informational contents consciousness can be modally and intramodally varied, selective and specific (Metzinger, 1995; Searle, 1997; Koch, 2004; Tononi, 2010). Consciousness has its contents in the form of feelings and sensations, perceptions, memories, and imagery dynamically representing external and/or internal environment in subject's experience. The representational contents can be processed by brain unconsciously or pre-consciously and only part of the processed perceptual- or memory-contents reach the status of being phenomenally/explicitly experienced (Dixon, 1981; Greenwald et al., 1996; Kinoshita and Lupker, 2003; Goodale and Milner, 2004; Dehaene et al., 2006; Dijksterhuis and Nordgren, 2006; van Gaal and Lamme, 2011). But what is the mechanism of consciousness? In the current debate the main question is: whether consciousness necessarily depends on the mechanism(s) of attention or can consciousness-level representation is possible without attention being applied. Increasingly more specialists, departing from theoretical arguments and empirical data accept that attention and consciousness are separate and different, however possibly interacting (e.g., Baars, 1997b; Hardcastle, 1997; Lamme, 2003; Bachmann, 2006; Koch and Tsuchiya, 2007; van Gaal and Fahrenfort, 2008; Wilimzig et al., 2008; Tsuchiya and Koch, 2009; Brascamp et al., 2010; van Boxtel et al., 2010a,b). Why this twist away from the earlier dominating views that consciousness needs attention? In what follows I will list the arguments in favor of attention and consciousness being dissociable, discuss why the controversy over the present issue persists, and suggest some steps for moving forward in a less confusing way.

\section{WHY IT CAN BE SAID THAT ATTENTION IS NOT THE BASIS FOR CONSCIOUSNESS}

There are many reasons for seeing why attention is not necessary for consciousness. First, maximum concentration of attention does not guarantee consciousness of a stimulus that is the focus of attention. In metacontrast masking, binocular rivalry, visual crowding, motion-induced blindness (MIB), and some other experimental phenomena of consciousness (Kim and Blake, 2005; Bachmann et al., 2011) loss of conscious experience of a targetstimulus is inevitable despite of the maximum attempts to attend to it. Binocular rivalry is perhaps the most used and discussed paradigm here.

Some recent work claiming that attention is necessary for binocular rivalry presents questionable evidence and conclusions e.g., Zhang et al. (2011). Frequency-tagged brain responses were induced for rivalrous stimuli with the effect that for the unattended stimulus this response was weak. However, the frequency-tagged brain response did not disappear under inattentional conditions but was simply weakened. The correlation between frequencytagged brain response and attentional condition is not a proof of a causal relation; this is especially if it is not sure that frequencytagged EEG signature is a valid NCC. Data and discussion presented by Roeber et al. (2011) points to the controversy over electrophysiological signatures as fully reliable NCC and also reinstates that rivalry continues while attention is diverted from the competing stimuli. 
Second, selective attention mechanisms are effective in improving processing of unconscious information. In many cases the nature and relative extent of the effect is comparable to those when attention improves processing of the consciously experienced stimuli. For example, attention can improve unconscious processing by augmenting priming effects or ERP components associated with pre-conscious processing (Jaśkowski et al., 2002; Naccache et al., 2002; Bahrami et al., 2007; Custers and Aarts, 2011). Conversely, unconsciously processed stimuli influence conscious attention and attention and awareness effects may be independent (Lambert and Shin, 2010; Schmidt and Schmidt, 2010; Hsieh et al., 2011; Hsu et al., 2011; Most and Wang, 2011; Tapia et al., 2011). The main difference is that in one case selective attention works on unconscious information and in the other case on consciously experienced information.

Third, attention can select between stimuli that are already, and to an equal extent, consciously perceived. Equally phenomenally salient perceptual objects precede attentional selection. Fourth, research shows that conscious awareness has specialized brain mechanisms of its own that are not the very mechanisms of selective attention (Purpura and Schiff, 1997; Jones, 2001; Koch, 2004; Ribary, 2005; Tsubomi et al., 2011). Experimental work has also shown that electrophysiological signatures of the effects of attention and awareness, especially when studied by the contrastive methods, can be different or independent (Kiefer and Brendel, 2006; Wyart and Tallon-Baudry, 2008; Aru and Bachmann, 2009a,b; Busch et al., 2009; Britz and Pitts, 2011).

The fifth argument derives from the experiments showing that in some specific conditions attention has an adverse effect on conscious experiences (Lou, 2001; Tsuchiya and Koch, 2009; Rahnev et al., 2011). Voluntary covert attention to color afterimage, afterimage of spatially modulated contrast, or spatially localized motion aftereffect tends to speed up their decay from awareness (Lou, 2001; Suzuki and Grabowecki, 2003; Wede and Francis, 2007; Bachmann and Murd, 2010; van Boxtel et al., 2010a; Murd and Bachmann, 2011). Sixth, some aspects of a scene such as the gist or animated objects can be explicitly noticed without attention and without compromising the competing focused attention task (van Boxtel et al., 2010b; see, however, Cohen et al., 2011). Seventh, consciousness-level sentience can in principle emerge spontaneously and without a preset selective attention. The typical cases are waking from sleep where one does not pay attention to the need to wake up now (while in sleep, we do not decide to begin attending to the environment) or involuntary hallucinating or tinnitus-like experiences.

On the other hand, nobody denies strong and very common examples where attention facilitates conscious experiences and often is the sine qua non-condition for conscious perception. These examples come from the phenomena of spatial and object attention, divided attention, prior entry, change blindness, inattentional blindness, working-memory analysis, understanding a demanding intellectual problem, etc. (Mack and Rock, 1998; Posner, 2004; Lavie, 2006; Srinivasan, 2007; Carrasco, 2011). Thus why the controversy over attention versus consciousness continues?

\section{WHY THE CONTROVERSY OVER THE ATTENTION VERSUS CONSCIOUSNESS ISSUE STUBBORNLY PERSISTS}

In my opinion there are four main reasons for this.

1. Researchers seem to implicitly assume that the solution to the problem of relation between attention and consciousness mechanisms should be exclusive - either the attention $=$ consciousness, mechanism, view should win, or attention $\neq$ consciousness view take the upper hand. Actually, there is a possibility that attention mechanisms are part of the mechanisms influencing consciousness. Depending on the mode of its participating action on the consciousness mechanism, attention can have both facilitative and adverse effects on the phenomena of consciousness.

2. Either implicitly or explicitly, specialists tend to limit their repertoire of brain mechanisms underlying cognition and affect too much restrictively. There are acknowledged mechanisms of sensation/perception (for building up representations), affect, memory storage, attention (as the selection device between objects or space-time locations or both), cognitive control and efferent control, and execution. The job of giving rise to consciousness is assumed to be accomplished by some of the listed mechanisms or combination of their activities. However, things become more tractable and also more consistent with neurobiological realities when we add a special mechanism to the list - a specialized mechanism for upgrading or modulating the data provided by the representational mechanism up to the level sufficient for direct phenomenal experience of its contents. Why so? First of all, the mechanisms for the listed specialized functions can work pre- or unconsciously (Dixon, 1981; Greenwald et al., 1996; Kinoshita and Lupker, 2003; Goodale and Milner, 2004; Dehaene et al., 2006; Dijksterhuis and Nordgren, 2006; Fiacconi and Milliken, 2011; van Gaal and Lamme, 2011; Zmigrod and Hommel, 2011). Quite specific perceptual and conceptual content can be discriminated by the brains in vegetative state and under anesthetic sedation (Kotchoubey, 2005; Laureys and Tononi, 2010). Thus it is a logical option to consider a mechanism dedicated to producing the changes in the processed contents so that they become explicitly experienced, a mechanism in addition to the listed ones. While often this function has been given to the attention mechanisms, the facts that attention is either independent of, insufficient for, or works against target information awareness (Hardcastle, 1997; Lou, 2001; Lamme, 2003; Koch and Tsuchiya, 2007; van Gaal and Fahrenfort, 2008; Wilimzig et al., 2008; Tsuchiya and Koch, 2009; Bachmann and Murd, 2010; Brascamp et al., 2010; van Boxtel et al., 2010a,b; Carlson et al., 2011; Hsu et al., 2011; Kaunitz et al., 2011; Lathrop et al., 2011; Morgan, 2011; Murd and Bachmann, 2011; Shin et al., 2011; Watanabe et al., 2011) suggest the need for a specialized consciousness mechanism. (This standpoint is even more strengthened by sound arguments about the non-existence of attention - Anderson, 2011). If specific perceptual encoding and attention cannot explain conscious experience as a dependent variable in the experiments, something else should. Furthermore, mechanisms of attention are heavily modality-specific (although work according to similar general principles), but conscious experience 
is integrated and unitary intermodally. The general anesthetics act on consciousness in a modality-invariant way, thus hinting at a common mechanism (Hudetz and Pearce, 2010). Importantly, the suggestion to add a specialized consciousness mechanism to the typical list is not founded on a mere speculation because neurobiological facts prove the existence of such mechanisms. Having no specialized function of specific processing of perceptual contents and being also not a dedicated selective attention mechanism, this mechanism is responsible for regulating the level of cortical processing by modulating the activity of specific content-representing mechanisms (Magoun, 1958; Mass and Smirnov, 1970; Llinás and Ribary, 2001; John, 2005; Ribary, 2005). Sufficient facilitative and oscillatory modulation is the precondition for consciousness. Earlier, I have suggested perceptual retouch as a panmodal or intermodally steered, universal mechanism that itself does not carry informational contents, that is autonomous from the mechanism of attention (although can be influenced by it) but is necessary for upgrading the pre-consciously processed representational contents to the consciousness-level (Bachmann, 1984, 1994, 1999, 2000). Thus, and importantly, there is a conceptual need for the conscious-status-"awarding” (CSA) mechanism, whether retouch or something else. Now, instead of asking whether consciousness mechanism is the attention mechanism and vice versa we just ask how the attention mechanism can influence the retouch- (i.e., CSA-) mechanism. Also, whether the effect is always facilitative or can it be sometimes also restrictive, independent, or even adverse. Why the perception mechanism cannot be used for this purpose is simple - perceptual representations - whether dynamic process kind of representations or more structural ones - can be and when related to the possibly available memory information, mostly are, pre- or unconscious. Why the attention mechanism cannot be the consciousness mechanism is also simple - there are too much experimental data showing irrelevance or adverse relation of attention with regard to consciousness.

3. When discussing the attention versus consciousness issue, the prevailing style has been to remain either overly abstract (i.e., consciousness as such, but not asking consciousness how) when speaking about consciousness or too much restricted to the specific perceptual/attentional phenomena as examples of consciousness. At the same time, no universal, intermodal attributes of conscious experience have been the main substance of discussion.

4. In tackling the issue of attention versus consciousness an often present implicit confusion tends to make the debates unfruitful. Surprisingly often the processes of attention are not clearly distinguished from the results of these processes as they take one or another form of experience. It is easily possible that when attention aids consciousness then selection among the candidate objects or locations is carried out by the attention mechanism (either bottom-up evoked or top-down controlled), but the results of this selection as experienced at the phenomenal level (e.g., enhanced clarity in consciousness of the attended object) are determined by some mechanism other than attention. Attention interacts with that other mechanism (e.g., the CSA), which results in a qualitatively different phenomenal experience. Taking into account all four above considerations, let me suggest an approach for how to choose the super-modal attributes of phenomenal perception in order to evaluate them in terms of the effects of attention. Let us see what the effects of attention look like when we analyze them with regard to these attributes as surfacing in published research and common scientific knowledge. Thereafter, I will suggest also some other potentially useful steps for moving forward.

\section{SOME SUGGESTIONS}

The principal modality-invariant attributes of phenomenal experience in the context of the present article are as follows:

- presence of phenomenal experience (either there is or there is not)

- subjective clarity of phenomenal experience (e.g., vividness, PAS level, etc.)

- selective emphasis in phenomenal experience (e.g., focus)

- duration of phenomenal experience (e.g., short-lived or longer)

- post-perturbation delay of phenomenal experience (e.g., stimulus perception latency)

- veridicality of content of phenomenal experience (e.g., illusory, distorted, etc.).

All six listed attributes are emphasized or augmented when CSA is activated (Mass and Smirnov, 1970; Bachmann, 1994; Baars, 1997a; Ribary, 2005). What about attention? In the following table the typical or expected effects of attention on the principal phenomenal attributes are systematized. Some of the table entries indicate the effects consistent with published experimental facts, some refer to the effects yet to be tested. (It can be easily concluded that the effects are very much dependent on what empirical phenomena we are considering).

Now, based on the table, let us compare some examples of the attentional effects. By la we specify phenomena where attention facilitates detection or description of the presence of target objects such as in the change blindness displays (Jensen et al., 2011), covert spatial pre-cueing (Carrasco, 2011), bottom-up popout in filtering tasks (Itti et al., 2005), partial report selection from iconic memory (Ruff et al., 2007; Sligte et al., 2010), etc. By 1b we specify effects of attention counteracting awareness, such as in the MIB (Schölvinck and Rees, 2009). By 1c we specify animal object detection (van Boxtel et al., 2010b), understanding that one is awake and present in the habitat after spontaneous awakening, involuntary perception of the alternatives in rivalry displays

Effects of attention on phenomenal attributes of consciousness.

\begin{tabular}{llll}
\hline Attribute & $\begin{array}{l}\text { a: Attention } \\
\text { facilitates }\end{array}$ & $\begin{array}{l}\text { b: Attention } \\
\text { counteracts }\end{array}$ & $\begin{array}{l}\text { c: Attention- } \\
\text { independent }\end{array}$ \\
\hline Presence (1) & Yes & Yes & Yes \\
Clarity (2) & Yes & $?$ & No \\
Selective emphasis (3) & Yes & No & No \\
Duration (4) & Yes & Yes & $?$ \\
Post-stimulus delay (5) & Yes & No & $?$ \\
Veridicality (6) & Yes & Yes & $?$
\end{tabular}


(Kim and Blake, 2005), attentional blink to the second target (Dux and Marois, 2009), delusional compulsory experiences, etc. By 2a such effects can be listed as covert spatial attention (Störmer et al., 2009; Carrasco, 2011), vividness of subjective experiences dependent on arousal states, etc. The entry 3 a refers to the selective attention effects in visual search, scene analysis, bottom-up and top-down spatial attention, dichotic listening, selection from iconic memory, etc. (Itti et al., 2005; Sligte et al., 2010; Bachmann et al., 2011). The entry 4a refers to increase of apparent duration by attention (Seifried and Ulrich, 2011) while $4 \mathrm{~b}$ refers for example to the adverse effect of attention on the duration of afterimages (van Boxtel et al., 2010a; Murd and Bachmann, 2011). For 5 a there are phenomena such as prior entry under attention (Hilkenmeier et al., 2011), release from masking by a pre-cue in perceptual latency priming (Scharlau and Neumann, 2003), perceptual facilitation in flash-lag displays (Nijhawan and Khurana, 2010), selective spatial attention by pre-cueing (Carrasco, 2011), etc. With $6 \mathrm{a}$ we refer to the cases where attending increases correct discrimination and content perception (Itti et al., 2005; Carrasco, 2011) while $6 \mathrm{~b}$ refers to the adverse effects of attention on veridicality of perception. The selection of examples for the latter is surprisingly rich: illusory percepts due to expectancy, stereotypical distortions because of learning effects, bias effects from frequency of use or experimenter effects, etc.

In the table the most interesting cases are where attention can have mutually opposite effects (e.g., $1 a-1 b, 4 a-4 b, 6 a-6 b)$. This may be interpreted as evidence against attention being the mechanism of consciousness, which is the view supported in this paper. However, this interpretation can be consistent with two different views on the issue of relations between attention and consciousness. For one view, assuming that attention is the very mechanism of consciousness the above contradictory facts are detrimental. However, if we take a broader view and assume that attention is only one of the many mechanisms having an impact on the work of the consciousness mechanism then there is an easy way to understand why attention can have opposite effects on conscious experience. In this it-depends-type of view attention simply has one or another effect on consciousness depending on how it is applied onto perceptual data processing.

Here is an analogy: blowing air on the flame can either ignite and facilitate fire or exterminate it, depending on the intensity and time of action on the flame. If attention is the ambient "wind" and consciousness is the "flame," a sufficiently strong and durable attending can speed up the decay of conscious experience (e.g., with afterimage experience). Yet, when air is standstill and no wind is present, the flame still burns. Attention as a mechanism that itself is not a consciousness mechanism can lead also to both the increase of veridicality of perception or increase of non-veridicalities. This depends on whether the bottom-up perceptual data or top-down, memory based, and expectancy-controlled information is fostered relatively more by attention. But what is clear though is that attention is neither sufficient nor necessary for consciousness in general. It alone cannot explain the various phenomena. It also need not guarantee consciousness of content when steadily applied on a sensory experience having that content. However, it may be necessary for some aspects of consciousness to show up (e.g., extreme clarity or priority in entry) or take one or another value (e.g., duration of experience).
If none of the different traditional mechanisms is separately sufficient for consciousness then a nagging question emerges: what is different in the activities of the constituent mechanisms of the unspecialized set of traditional mechanisms when consciousness with its content emerges? I do not have a good answer to this. As we saw above, attention cannot be the decisive mechanism. Perceptual and memory representation can be and often largely are pre-conscious. Cognitive control does not have content. Intuitively, it seems more natural that there is a mechanism specialized for "awarding" consciousness quality for the representational contents mediated by the specific, specialized memory systems and perceptual content systems. In this case with CSA at hand it is easier to understand why attention in one case facilitates consciousness of contents and in some other case does not or even dampens it. Attention as the principal mechanism of selection out of alternative informational options can either facilitate the working or use of the CSA or inhibit (or abstain from use of) it.

The likely possibilities of relationship between attention mechanisms and the CSA mechanism are as follows: (1) attention mechanism acting upon CSA, which in turn leads to either facilitation of consciousness-level microgenesis of the explicit experience or to inhibition of the consciousness of target; (2) attention mechanism and CSA acting independently and in parallel first, only then followed by mutual interaction (e.g., conscious experience capturing attentional resources, or attentionally amplified pre-conscious representation capturing CSA resources). Which one of the above relationships is valid or whether both can be implemented requires special research in future.

At present there are several candidate mechanisms for acting as the special mechanistic intermediate between preconscious information-representing activity and conscious-level information-representing means. In the family of thalamocortical interaction theories assuming a special role for the so-called nonspecific-thalamic units for upgrading the pre-conscious cortical contents there are several varieties (e.g., Magoun, 1958; Bachmann, 1984, 1999, 2007; Bogen, 1995; Newman, 1995; Baars, 1997a; Purpura and Schiff, 1997; Llinás and Ribary, 2001; John, 2005; Ribary, 2005; Ward, 2011). Despite the "family resemblances," these researchers think that the pre-conscious cortical contents quite reliably represented after specific relay units transfer information from receptors to cortical modules become conscious contents as soon as they are modulated by thalamocortical general-purpose activity (the CSA mechanism). In some of the models post-synaptic EPSPs of the content-carrying cortical neurons are the targets for non-specific-thalamic modulation (e.g., Bachmann, 1994). In other models oscillating activity of the specific representational neurons and non-specific modulation-system neurons becomes synchronized for consciousness with its specific content to emerge (Llinás and Ribary, 2001; John, 2005). In a recent conceptualization termed "binding binding” Bachmann (2007) envisaged two processes of binding by oscillatory synchrony - first-order binding of features into perceptual objects by synchronizing feature-specific neurons pre-consciously and second-order binding of the bound pre-conscious objects into general consciousness-level representation. The second-order binding is executed via the oscillations of the non-specific CSA system. In this version, a representation is essentially a dynamic representation. Attentional 
network can be though either to aid pre-conscious binding, binding for consciousness, or exhausting (or desynchronizing) the oscillatory resources in case of adverse effects on consciousness.

In the reentrant theory it is assumed that for the specific contents represented by primary sensory cortices to become consciously represented, they need to be accessed by the reentrant signals from the higher-order cortical nodes sent back to the already activated earlier units (Lamme, 2003; van Gaal and Lamme, 2011). Bottom-up plus top-down cycles of mutual activation are sufficient for consciousness of its contents. In this theory the mechanism is not neuroanatomically distinct (albeit interacting with differently placed other modules) as is the case with thalamic theories. It is functionally defined, implemented by the neural units that are neuroanatomically the same. Although Lamme and van Gaal explain attentional effects both independent and associated with consciousness, there are some questionable aspects to this theory. First of all, it would be computationally and adaptively suspect to leave both the functions of representation and modulation to the units of the same neural system. One and the same structural system should have difficulty in transforming from content-representing system to a control system and vice versa, unless some mystique would be brought in.

Let me end with a few concluding remarks. In order to better understand the nature of attention and consciousness and their relation (i) some conceptual distinctions either absent or only implicitly involved in theorizing so far are necessary. This applies to the distinction between: processes and dynamic results of the

\section{REFERENCES}

Anderson, B. (2011). There is no such thing as attention. Front. Psychol. 2:246. doi:10.3389/fpsyg.2011.00246

Aru, J., and Bachmann, T. (2009a). Boosting up gamma-band oscillations leaves target-stimulus in masking out of awareness: explaining an apparent paradox. Neurosci. Lett. 450, 351-355.

Aru, J., and Bachmann, T. (2009b). Occipital EEG correlates of conscious awareness when subjective target shine-through and effective visual masking are compared: bifocal early increase in gamma power and speed-up of P1. Brain Res. 1271, 60-73.

Baars, B. (1997a). In the Theater of Consciousness. Oxford: Oxford University Press.

Baars, B. (1997b). Some essential differences between consciousness and attention, perception and working memory. Conscious. Cogn. 6, 363-371.

Bachmann, T. (1984). The process of perceptual retouch: nonspecific afferent activation dynamics in explaining visual masking. Percept. Psychophys. 35, 69-84.
Bachmann, T. (1994). Psychophysiology of Visual Masking: The Fine Structure of Conscious Experience. Commack, NY: Nova Science Publishers.

Bachmann, T. (1999). "Twelve spatiotemporal phenomena, and one explanation," in Cognitive Contributions to the Perception of Spatial and Temporal Events, eds G. Aschersleben, T. Bachmann, and J. Müsseler (Amsterdam: Elsevier), 173-206.

Bachmann, T. (2000). Microgenetic Approach to the Conscious Mind. Amsterdam, Philadelphia: John Benjamins.

Bachmann, T. (2006). "Microgenesis of perception: conceptual, psychophysical, and neurobiological aspects," in The First Half Second: The Microgenesis and Temporal Dynamics of Unconscious and Conscious Visual Processes, eds H. Ögmen and B. G. Breitmeyer (Cambridge, MA: MIT Press), 11-33.

Bachmann, T. (2007). Binding binding: departure points for a different version of the perceptual retouch theory. Adv. Cogn. Psychol. 3, 41-55.

Bachmann, T., Breitmeyer, B. G., and Ögmen, H. (2011). The Experimental Phenomena of Consciousness: A Brief Dictionary Revised Edition. New York: Oxford University Press.

processes; content-specific attributes of conscious experiences and universal, content-invariant attributes of conscious experiences; possibly opposite effects of the same mechanism (e.g., attention) on consciousness depending on the characteristics of influence that the same mechanism has. Also, (ii) it may be advisable to abandon both the attention-as-consciousness, view, and the view that consciousness emerges by default from the work of traditional mechanisms of perception, memory, and attention. Instead, let us find a deserved place for the special mechanism of consciousness in addition to the perceptual, attentional, memory, cognitive control, and other standard mechanisms long acknowledged. Methodologically, (iii) in addition to the mostly correlational studies (NCC) more mechanistic and causal-effects related research is needed. Let us accept that there is a special (thalamocortical interactive?) mechanism and a corresponding theoretical mechanistic concept for the dedicated CSA brain process(es) responsible for upgrading pre-conscious results of the perception up to the consciousnesslevel results. This concept is functionally apart from the concepts of perception and attention. Therefore, we may have better chances to solve the attention versus consciousness puzzle. Indeed, both perception and attention can be independent of the explicit conscious experience.

\section{ACKNOWLEDGMENTS}

I appreciate the support from Estonian Ministry of Education and Research and the Scientific Competency Council through the targeted financing research theme SF0182717s06, "Mechanisms of Visual Attention."

Bachmann, T., and Murd, C. (2010) Covert spatial attention in search for the location of a color-afterimage patch speeds up its decay from awareness: introducing a method useful for the study of neural correlates of visual awareness. Vision Res. 50, 1048-1053.

Bahrami, B., Lavie, N., and Rees, G. (2007). Attentional load modulates responses of human primary visual cortex to invisible stimuli. Curr. Biol. 17, 509-513.

Bogen, J. E. (1995). On the neurophysiology of consciousness: I. An overview. Conscious. Cogn. 4, 52-62.

Brascamp, J. W., van Boxtel, J. J., Knapen, T., and Blake, R. (2010). A dissociation of attention and awareness in phase-sensitive but not phaseinsensitive visual channels. J. Cogn. Neurosci. 22, 2326-2344.

Britz, J., and Pitts, M. A. (2011). Perceptual reversals during binocular rivalry: ERP components and their concomitant source differences. Psychophysiology 48, 1489-1498.

Busch, N. A., Dubois, J., and VanRullen, R. (2009). The phase of ongoing EEG oscillations predicts visual perception. J. Neurosci. 29, 7869-7876.

Carlson, J. M., Reinke, K. S., LaMontagne, P. J., and Habib, R.
(2011). Backward masked fearful faces enhance contralateral occipital cortical activity for visual targets within the spotlight of attention. Soc. Cogn. Affect. Neurosci. 6, 639-645.

Carrasco, M. (2011). Visual attention: the past 25 years. Vision Res. 51, 1484-1525.

Cohen, M. A., Alvarez, G. A., and Nakayama, K. (2011). Natural-scene perception requires attention. Psychol. Sci. 22, 1165-1172.

Custers, R., and Aarts, H. (2011). Learning of predictive relations between events depends on attention, not on awareness. Conscious. Cogn. 20, 368-378.

Dehaene, S., Changeux, J. P., Naccache, L., Sackur, J., and Sergent, C. (2006). Conscious, preconscious, and subliminal processing: a testable taxonomy. Trends Cogn. Sci. (Regul. Ed.) 10, 204-211.

Dijksterhuis, A., and Nordgren, L. F. (2006). A theory of unconscious thought. Perspect. Psychol. Sci. 1, 95-109.

Dixon, N. F. (1981). Preconscious Processing. Chichester: Wiley.

Dux, P. E., and Marois, R. (2009). The attentional blink: a review of data and theory. Atten. Percept. Psychophys. 71, 1683-1700. 
Fiacconi, C. M., and Milliken, B. (2011). On the role of attention in generating explicit awareness of contingent relations: evidence from spatial priming. Conscious. Cogn. 20, 1433-1451.

Goodale, M. A., and Milner, A. D. (2004). Sight Unseen: An Exploration of Conscious and Unconscious Vision. Oxford: Oxford University Press.

Greenwald, A. G., Draine, S. C., and Abrams, R. L. (1996). Three cognitive markers of unconscious semantic activation. Science 273 1699-1702.

Hardcastle, V. G. (1997). Attention versus consciousness: a distinction with a difference. Cogn. Stud. 4, 356-366.

Hilkenmeier, F., Olivers, C. N. L., and Scharlau, I. (2011). Prior entry and temporal attention: cueing affects order errors in RSVP. J. Exp. Psychol. Hum. Percept. Perform. doi:10.1037/a0025978

Hsieh, P.-J., Colas, J. T., and Kanwisher, N. (2011). Pop-out without awareness: unseen feature singletons capture attention only when top-down attention is available. Psychol. Sci. 22, 1220-1226.

Hsu, S.-M., George, N., Wyart, V., and Tallon-Baudry, C. (2011). Voluntary and involuntary spatial attentions interact differentially with awareness. Neuropsychologia 49, 2465-2474.

Hudetz, A., and Pearce, R. (eds). (2010). Suppressing the Mind. Anesthetic Modulation of Memory and Consciousness. New York: Humana Press.

Itti, L., Rees, G., and Tsotsos, J. K. (2005). Neurobiology of Attention. Amsterdam: Elsevier.

Jaśkowski, P., van der Lubbe, R., Schlotterbeck, E., and Verleger, R. (2002). Traces left on visual selective attention by stimuli that are not consciously identified. Psychol. Sci. 13, 48-54.

Jensen, M. S., Yao, R., Street, W. N., and Simons, D. J. (2011). Change blindness and in attentional blindness. Wiley Interdiscip. Rev. Cogn. Sci. 2, 529-546.

John, E. R. (2005). From synchronous neuronal discharges to subjective awareness? Prog. Brain Res. 150, 143-171.

Jones, E. G. (2001). The thalamic matrix and thalamocortical synchrony. Trends Neurosci. 24, 595-601.

Kaunitz, L., Fracasso, A., and Melcher, D. (2011). Unseen complex motion is modulated by attention and generates a visible aftereffect. J. Vis. 11, $1-9$.
Kiefer, M., and Brendel, D. (2006). Attentional modulation of unconscious "automatic" processes: evidence from event-related potentials in a masked priming paradigm. $J$. Cogn. Neurosci. 18, 184-198.

Kim, C.-Y., and Blake, R. (2005). Psychophysical magic: rendering the visible “invisible." Trends Cogn. Sci. (Regul. Ed.) 9, 381-388.

Kinoshita, S., and Lupker, S. J. (eds). (2003). Masked Priming: The State of the Art. New York: Psychology Press.

Koch, C. (2004). The Quest for Consciousness. Englewood: Roberts \& Co.

Koch, C., and Tsuchiya, N. (2007). Attention and consciousness: two distinct brain processes. Trends Cogn. Sci. (Regul. Ed.) 11, 16-22.

Kotchoubey, B. (2005). Event-related potential measures of consciousness: two equations with three unknowns. Prog. Brain Res. 150, 427-444.

Lambert, A. J., and Shin, M.-J. (2010). The hare and the snail: dissociating visual orienting from conscious perception. Vis. Cogn. 18, 829-838.

Lamme, V. A. F. (2003). Why visual attention and awareness are different. Trends Cogn. Sci. (Regul. Ed.) 7, 12-18.

Lathrop, W. B., Bridgeman, B., and Tseng, P. (2011). Perception in the absence of attention: perceptual processing in the Roelofs effect during in attentional blindness. Perception 40, 1104-1119.

Laureys, S., and Tononi, G. (eds). (2010). The Neurology of Consciousness: Cognitive Neuroscience and Neuropathology. Amsterdam: Elsevier.

Lavie, N. (2006). The role of perceptual load in visual awareness. Brain Res. 1080, 91-100.

Llinás, R., and Ribary, U. (2001). Consciousness and the brain. The thalamocortical dialogue in health and disease. Ann. N. Y. Acad. Sci. 929, 166-175.

Lou, L. (2001). Effects of voluntary attention on structured afterimages. Perception 30, 1439-1448.

Mack, A., and Rock, I. (1998). In Attentional Blindness. Cambridge, MA: MIT Press.

Magoun, H. W. (1958). The Waking Brain. Springfield: C. C. Thomas.

Mass, A. M., and Smirnov, G. D. (1970). Participation of the nonspecific system of the brain stem and thalamus in cortico-thalamic influences. Fiziol. Zh. SSSR Im. I. M. Sechenova 56, 1673-1681.

Metzinger, T. (ed.). (1995). Conscious Experience. Thorverton: Imprint Academic.
Morgan, M. J. (2011). Wohlgemuth was right: distracting attention from the adapting stimulus does not decrease the motion after-effect. Vision Res. 51, 2169-2175.

Most, S. B., and Wang, L. (2011). Dissociating spatial attention and awareness in emotion-induced blindness. Psychol. Sci. 22, 300-305.

Murd, C., and Bachmann, T. (2011). Spatially localized motion aftereffect disappears faster from awareness when selectively attended to according to its direction. Vision Res. 51, 1157-1162.

Naccache, L., Blandin, E., and Dehaene, S. (2002). Unconscious masked priming depends on temporal attention. Psychol. Sci. 13, 416-424.

Newman, J. (1995). Thalamic contributions to attention and consciousness. Conscious. Cogn. 4, 172-193.

Nijhawan, R., and Khurana, B. (eds). (2010). Space and Time in Perception and Action. Cambridge: Cambridge University Press.

Posner, M. I. (ed.). (2004). Cognitive Neuroscience of Attention. New York: Guilford.

Purpura, K. P., and Schiff, N. D. (1997). The thalamic intralaminar nuclei: a role in visual awareness. Neuroscientist 3, 8-15.

Rahnev, D., Maniscalco, B., Graves, T., Huang, E., de Lange, F. P., and Lau, H. (2011). Attention induces conservative subjective biases in visual perception. Nat. Neurosci. 14, 1513-1515.

Ribary, U. (2005). Dynamics of thalamo-cortical network oscillations and human perception. Prog. Brain Res. 150, 127-142.

Roeber, U., Veser, S., Schröger, E., and O'Shea, R. P. (2011). On the role of attention in binocular rivalry: electrophysiological evidence. PLoS ONE 6, e22612. doi:10.1371/journal.pone.0022612

Ruff, C. C., Kristjánsson, Á., and Driver, J. (2007). Readout from iconic memory and selective spatial attention involve similar neural processes. Psychol. Sci. 18, 901-909.

Scharlau, I., and Neumann, O. (2003). Perceptual latency priming by masked and unmasked stimuli: evidence for an attentional interpretation. Psychol. Res. 67, 184-196.

Schmidt, F., and Schmidt, T. (2010) Feature-based attention to unconscious shapes and colors. Atten. Percept. Psychophys. 72, 1480-1494.

Schölvinck, M. L., and Rees, G. (2009). Attentional influences on the dynamics of motion-induced blindness. J. Vis. 9, 1-9.

Searle, J. R. (1997). The Mystery of Consciousness. London: Granta Books.

Seifried, T., and Ulrich, R. (2011). Exogenous visual attention prolongs perceived duration. Atten. Percept. Psychophys. 73, 68-85.

Shin, M.-J., Marrett, N., and Lambert, A. J. (2011). Visual orienting in response to attentional cues: spatial correspondence is critical, conscious awareness is not. Vis. Cogn. 19, 730-761.

Sligte, I. G., Vandenbroucke, A. R. E., Scholte, H. S., and Lamme, V. A. F. (2010). Detailed sensory memory, sloppy working memory. Front. Psychol. 1:175. doi:10.3389/fpsyg.2010.00175

Srinivasan, N. (2007). Interdependence of attention and consciousness. Prog. Brain Res. 168, 65-75.

Störmer, V. S., McDonald, J. J., and Hillyard, S. A. (2009). Crossmodal cueing of attention alters appearance and early cortical processing of visual stimuli. Proc. Natl. Acad. Sci. U.S.A. 106, 22456-22461.

Suzuki, S., and Grabowecki, M. (2003). Attention during adaptation weakens negative afterimages. J. Exp. Psychol. Hum. Percept. Perform. 29, 793-807.

Tapia, E., Breitmeyer, B. G., and Broyles, E. C. (2011). Properties of spatial attention in conscious and nonconscious visual information processing. Conscious. Cogn. 20 , 426-431.

Tononi, G. (2010). Information integration: its relevance to brain function and consciousness. Arch. Ital. Biol. 148, 299-322.

Tsubomi, H., Ikeda, T., Hanakawa, T., Hirose, N., Fukuyama, H., and Osaka, N. (2011). Dissociable neural activations of conscious visibility and attention. J. Cogn. Neurosci. doi: 10.1162/jocn_a_00122. [Epub ahead of print].

Tsuchiya, N., and Koch, C. (2009). “The relationship between consciousness and attention," in The Neurology of Consciousness, eds S. Laureys and G. Tononi (Amsterdam: Elsevier, Academic Press), 63-77.

van Boxtel, J. J. A., Tsuchiya, N., and Koch, C. (2010a). Opposing effects of attention and consciousness on afterimages. Proc. Natl. Acad. Sci. U.S.A. 107, 8883-8888.

van Boxtel, J. J. A., Tsuchiya, N., and Koch, C. (2010b). Consciousness and attention: on sufficiency and necessity. Front. Psychol. 1:217. doi:10.3389/fpsyg.2010.00217 
van Gaal, S., and Fahrenfort, J. J. (2008). The relationship between visual awareness, attention, and report. J. Neurosci. 28, 5401-5402.

van Gaal, S., and Lamme, V. A. F. (2011). Unconscious high-level information-processing: implication for neurobiological theories of consciousness. Neuroscientist doi:10.1177/1073858411404079

Ward, L. M. (2011). The thalamic dynamic core theory of conscious experience. Conscious. Cogn. 20, 464-486.

Watanabe, M., Cheng, K., Murayama, Y., Ueno, K., Asamizuya, T., Tanaka, K., and Logothetis, N. (2011). Attention but not awareness modulates the
BOLD signal in the human V1 during binocular suppression. Science 334, 829-831.

Wede, J., and Francis, G. (2007) Attentional effects on afterimages: theory and data. Vision Res. 47, 2249-2258.

Wilimzig, C., Tsuchiya, N., Fahle, M., Einhäuser, W., and Koch, C. (2008). Spatial attention increases performance but not subjective confidence in a discrimination task. J. Vis. 8, $1-10$.

Wyart, V., and Tallon-Baudry, C. (2008). Neural dissociation between visual awareness and spatial attention. J. Neurosci. 28, 2667-2679.

Zhang, P., Jamison, K., Engel, S., and He, S. (2011). Binocular rivalry requires visual attention. Neuron 71 362-369.

Zmigrod, S., and Hommel, B. (2011) The relationship between feature binding and consciousness: evidence from asynchronous multimodal stimuli. Conscious. Cogn. 20, 586-593.

Conflict of Interest Statement: The author declares that the research was conducted in the absence of any commercial or financial relationships that could be construed as a potential conflict of interest.

Received: 14 September 2011; accepted: 08 December 2011; published online: 29 December 2011.
Citation: Bachmann T (2011) Attention as a process of selection, perception as a process of representation, and phenomenal experience as the resulting process of perception being modulated by a dedicated consciousness mechanism. Front. Psychology 2:387. doi: 10.3389/fpsyg.2011.00387

This article was submitted to Frontiers in Consciousness Research, a specialty of Frontiers in Psychology.

Copyright ( $\odot 2011$ Bachmann. This is an open-access article distributed under the terms of the Creative Commons Attribution Non Commercial License, which permits non-commercial use, distribution, and reproduction in other forums, provided the original authors and source are credited. 